\title{
Reconfiguring Industrial Policy: A Framework with an Application to South Africa
}

Ricardo Hausmann, Dani Rodrik, and Charles F. Sabel

CID Working Paper No. 168

May 2008

(C) Copyright 2008 Ricardo Hausmann, Dani Rodrik, Charles F. Sabel, and the President and Fellows of Harvard College

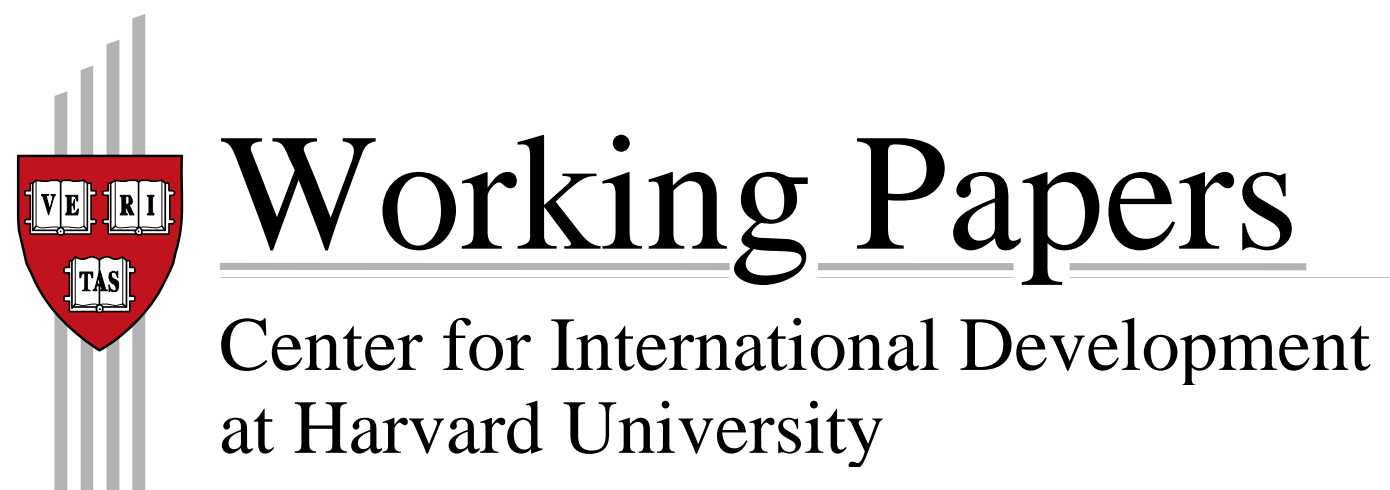




\title{
Reconfiguring Industrial Policy: A Framework with an Application to South Africa
}

\author{
Ricardo Hausmann, Dani Rodrik, and Charles F. Sabel
}

May 2008

\begin{abstract}
The main purpose of industrial policy is to speed up the process of structural change towards higher productivity activities. This paper builds on our earlier writings to present an overall design for the conduct of industrial policy in a low- to middle-income country. It is stimulated by the specific problems faced by South Africa and by our discussions with business and government officials in that country. We present specific recommendations for the South African government in the penultimate section of the paper.
\end{abstract}

Keywords: industrial policy, South Africa

JEL Codes: O25

This paper is part of the CID South Africa Growth Initiative. This project is an initiative of the National Treasury of the Republic of South Africa within the government's Accelerated and Shared Growth Initiative (ASGI-SA), which seeks to consolidate the gains of post-transition economic stability and accelerate growth in order to create employment and improve the livelihoods of all South Africans. For more information and the entire series of papers, visit the project's web site at http://www.cid.harvard.edu/southafrica. 


\title{
RECONFIGURING INDUSTRIAL POLICY: \\ A FrAMEWORK WITH AN APPLICATION TO SOUTH AFRICA *
}

\author{
Ricardo Hausmann, Dani Rodrik, and Charles F. Sabel
}

Revised

August 31, 2007

\section{Introduction}

In this paper, we build on our earlier writings to present an overall design for the conduct of industrial policy in a low- to middle-income country. Our reflections have been stimulated by the specific problems faced by South Africa and by our discussions with business and government officials in that country. In the penultimate section of the paper, we present specific recommendations for the South African government. However, we expect these ideas to have wide relevance to a range of other countries as well. We take the main purpose of industrial policy to be to speed up the process of structural change towards higher productivity activities. This is a challenge that is common to all developing countries.

We begin by presenting the main differences of our approach from the traditional conception of industrial policy. We next lay out a two-pronged approach, entitled industrial policy in the "small" and industrial policy in the "large." Lastly, we discuss our policy recommendations for South Africa.

\section{The policy problem}

The traditional way in which economists think about policy is to first identify distortions which prevent market prices from signaling real marginal social costs and then to design taxes or subsidies that can reduce the identified gaps. Market failures of this sort are presumed to be few and far in between, and therefore the need for intervention by the government tends to be the exception rather than the rule. Private actors in the traditional view play little or no role in designing these public solutions: either they free ride on the efforts of others who are presumed to have an interest in addressing the problems, or they prefer to lobby for solutions that serve their particular interests at the expense of the public.

This way of thinking about policy leads to the long-standing and by now entirely familiar debate on the pros and cons of industrial policy. On the one side, we have advocates who point to the magnitude of the observed or presumed market failures and call for robust interventions in response. On the other, we have the skeptics who point to

* We thank Dana Brudowsky for editorial assistance. 
the near-impossibility of precisely locating the imperfections in question and to the likelihood that rent-seeking firms can and will take the government for a ride.

We depart from the traditional framework in a number of ways. We believe our departures give us a better handle on industrial policy while helping us move beyond the stale debates about its feasibility and desirability.

To begin, we presume that in a developing country the relevant market failures are not a rarity but rather a rampant feature of the landscape. The market failures that demand industrial policy - i.e., interventions that have differential effects on some economic activities over others - take three forms in particular:

a) Self-discovery externalities: Learning what new products can be produced profitably in an economy, and how, is an activity whose social value greatly exceeds its private value.

b) Coordination externalities: New economic activities often require simultaneous and lumpy investments upstream, downstream, and in parallel forks, which decentralized markets are not good at coordinating.

c) Missing public inputs: Private production typically requires highly specific public inputs - legislation, accreditation, R\&D, transport and other infrastructure specific to an industry - of which the government has little ex-ante knowledge.

In reality, missing public inputs are a form of coordination externality with the added complexity that the requisite public inputs lack proper markets to generate information and incentives - and even if they did exist, the government, not being a profitmaximizing institution, would not automatically respond to the signals generated.

We believe that the three types of market failures lie behind slow structural transformation, and hence low economic growth. (We do not want to minimize the role of obvious government failures such as poor governance, corruption, and lousy macroeconomic management, but we think the latter are inadequate to explain slow growth in general).

However, we assume that neither economists and public officials, on the one side, nor private actors, on the other, know where the relevant distortions are. A key feature of the policy process is to identify them, or, more precisely, to organize "searches" to identify and respond to them.

Furthermore, we assume that these distortions are very high dimensional. They implicate many different markets and inputs, each relatively specific to a variety of existing and potential activities. Solutions to the distortions correspondingly require 
complex bundles of measures of various kinds. The space that needs to be searched to assemble such bundled solutions is therefore very large.

Consequently, most of the distortions cannot be addressed through appropriate first-best Pigovian cash subsidies or money transfers. Instead, they reflect missing markets or public inputs (infrastructure, industry-specific skills, regulation, property rights, and social norms). So seen from this vantage point too the requisite solutions involve a portfolio of measures or activities (e.g., building specific infrastructure while passing certain laws, regulating certain markets, and providing certain services) which cumulate into purposeful capabilities (e.g., being able to transport and sell fresh meat in a foreign market). Transfers of money do not create the equivalent effect.

The nature of market failures in any country is determined by and embedded in the pre-existing patterns of specialization of that country. These market failures are not universal or free floating. What a country produces successfully reflects its current capabilities. In particular, it reflects its capacity to overcome those coordination failures and other market failings that would have otherwise severely limited the efficiency of existing activities or would have prevented their existence altogether. Given the difficulty in coordinating the creation of capabilities for activities that do not yet exist, productive transformation tends to favor "nearby" goods, in other words goods that require capabilities that are similar to those that already exist in the country.

With the expectation that rapid development will continue to go hand in hand with vertiginous changes in products and production processes, public inputs regarding practices such as regulation and certification must increasingly allow and even encourage differentiation in their application and on-going specification of their central purposes. Thus in domains as diverse as financial regulation, phytosanitary conditions, air traffic safety, and water quality, the state, or the state acting under the umbrella of an international agreement, now sets minimal and explicitly provisional framework goals. Private or local actors are obligated to establish a plan for meeting the goals and then to show that they are actually doing so. The original goals and the methods of monitoring progress towards them are periodically revised in the light of this experience. The obligations arising under these frameworks can only be met locally, and often only with the help of highly specialized public inputs - for instance, assistance to private actors in "complying" with the changing requirements by scanning the outside world for new developments more regularly and extensively than before.

Self-discovery - investigation of what markets an enterprise or entrepreneur can (come to be able to) serve - is an on-going process in the economy. Firms are constantly trying to identify the market opportunities arising from changing social needs and patterns of economic cooperation and to exploit them by designing products that incorporate novel production, social, and organizational technologies.

Self-discovery is also increasingly collaborative in that firms seeking to enter a new market must demonstrate not just the ability to produce a certain component or product, but also the ability to improve its design or the process by which it is produced 
in cooperation with the potential customer. Firms may need public inputs to help them acquire the capacities needed for this kind of collaboration, just as they may need public inputs to meet the obligations of framework regulation.

Firms, individually as well as in sector or domain-specific clusters that are engaged in self-discovery, are also willy-nilly mapping out the distortion space; in evaluating possible next steps they consider, among other things, whether it is worthwhile to reduce certain inefficiencies in current operations or to attempt to remove obstacles that led to displacement away from particular lines of business. The private sector thus acquires knowledge that is indispensable to the identification and elimination of high dimensional, non-monetizable distortions.

Nonetheless, the self-discovery searches of firms and entrepreneurs are subject to distortions and coordination problems of their own. Search is costly, and its returns uncertain. Ideas can be copied, to the benefit of the imitator but not the originator. In general firms will under-invest in searches that provide "public" benefits and will seek to prevent competitive entry. This limits industrial take-off. When we do observe rapid self-discovery, it is typically in those cases where the externalities are somehow internalized. Two sorts of examples come to mind: first, when the relevant activities are internalized within a single large firm (as with Japanese zaibatsu and Korean chaebols), and second, when the promoter can figure out how to make money from diffusion (as in selling new or improved seeds or packing and trading the final product). The private sector is in this sense no closer to omniscience and omni-competence than the public sector is.

Finally, many forms of Pareto-improving cooperation among private firms are not self-enforcing. They are voluntary at the time of agreement, but require enforcement at the time of execution. Governments may have a comparative advantage at enforcement, but they need to be part of the entire process of designing, enacting and revising laws and regulations if they are to use their enforcement powers effectively.

As such, the private sector needs the government to help internalize the various externalities associated with the cost-discovery process and to provide many of the public inputs (standards, infrastructure, certification, property rights) that only the government can. The government in turn requires the cooperation of firms and entrepreneurs because it needs to elicit the relevant information about the obstacles and opportunities they face and because it has to be able to influence their behavior in the desired direction. Hence the necessity of collaboration between the two sectors in the search for distortions and their solutions. Our understanding of what industrial policy does (or should do) takes this necessity as its starting point. We take "good" industrial policy to consist of those institutional arrangements and practices that organize this collaboration effectively.

\section{$\underline{\text { III. From principles to policies }}$}


Where does this understanding of industrial policy leave us with respect to actual, concrete policies? In the traditional understanding of industrial policy, formed within the standard view of market failure, the policy instruments are relatively easy to enumerate: tariff protection, tax rebates, $R \& D$ subsidies, directed credit, industrial zones, and so on. These instruments are put in the service of a number of priority sectors, such as autos, call centers, or bio-technology. The priority sectors at any moment are those thought to have, by their nature, certain appealing features and a preponderance of the relevant market failures: for instance, investments in them are held to induce important complementary investments, to represent the next step in the developmental sequence appropriate to an economy of a particular type, or to facilitate the climb of domestic industry up global supply chains. Our approach, by contrast, puts the emphasis on getting the strategic collaboration with the private sector which directs policy to work right. It can say very little ex-ante about either the instruments to be used or the economic activities to be promoted. Our recommendations therefore tend to be oriented towards processes and procedures for selecting (and correcting selections) of both, rather than specific policy instruments or sectors.

We emphasize that this is not a weakness: it is central to how we think governments ought to be organizing their industrial policies. A government should evaluate its industrial policy framework not by asking questions of the type: which tax breaks or subsidies are we using? which sectors have we identified? what is the budget we have allocated for industrial promotion? The relevant questions instead are: have we set up the institutions that engage the bureaucrats in an ongoing conversation of pertinent themes with the private sector, and do we have the capacity to respond selectively, yet also quickly and using a variety of updated policies, to the economic opportunities that these conversations are helping identify? Our impression is that the answers in South Africa to both of these questions are, at present, no and no.

With this background in mind, we propose that industrial policy activities be oriented around two different axes, one that works "locally" to improve the performance of existing industries through stepwise increases in their capacities, and the other that works "globally" through strategic bets on new industries whose success depends on bigger capacity leaps. We sketch below what these activities might look like, in the hope that this will also provide some concreteness to the approach that we are advocating.

\section{Industrial policy "in the small."}

A parsimonious strategy for industrial policy would focus on existing economic activities, and consist of putting mechanisms in place to ensure that roadblocks facing these activities can be identified and removed. Such a strategy is based on improving the provision of public inputs to existing activities with the hope that this will lead to higher productivity and quality for existing activities and a higher likelihood that nearby products will emerge. As we argued above, the best sources of information for the identification and co-development of public inputs are existing firms. This differentiates 
this approach from strategic bets (discussed next), where the relevant actors may not yet exist.

The government faces a three-fold problem here. First, it has an information problem: it does not know what public inputs it needs to provide. Second, even if the government knew what was needed, it also faces an incentive problem: officials may receive ineffectual, weak rewards for taking the "appropriate" actions. More seriously, the rewards for rent provision may be greater than the rewards for productivity enhancement. Finally, it faces a resource problem: as opposed to the market, it does not have an automatic mechanism for resources to move to fill the identified needs.

Our proposal is designed to overcome these obstacles. It involves four elements:

a) A mechanism to promote, under public auspices, systematic discussion among firms with the aim of identifying, and proposing solutions to, specific coordination failures.

b) A new budgetary procedure to increase the responsiveness of the public sector to the requisite actions.

c) A new monitoring procedure to discipline project selection while diffusing the lessons of its successes.

d) A set of operating principles.

The first piece of the intervention consists of organizing the dialogue with the private sector. Here we would propose the creation of a specific institutional mechanism - which in the East Asian context is often called a "deliberation council" - at the appropriate level of aggregation. Too aggregated a discussion would lead to proposals that are good for everybody in the room, like a tax holiday, but not really related to the identification of specific public inputs. Too narrow would be unmanageable. An ideal approach would be for the groups to self-organize. The fact that participation would lead to the supply of public inputs should be enough of an incentive. However, there may be a case to provide some incentive to overcome the free-rider problem or to help (groups of) firms that lack the capacity to specify their needs for public inputs.

Depending on what purpose they see themselves serving, existing industry associations and chambers may or may not be the right fora for this. Groupings organized around solving common "technical" problems of an industry - and thus in effect defining which bundles of public inputs will help to overcome particular distortions - will generally be more appropriate than associations whose main purpose is to lobby for standard forms of government aid. Nor should we think of these groupings as being organized solely around conventional industry lines. The need for skilled craftsmen (electricians, plumbers, machine tool operators) cuts across industry codes. A port expansion project will have as its clients many industries that rely on foreign trade in particular regions of the country. Once again, allowing self-organization rather than 
imposing preconceived structures on these deliberations is crucial. We imagine that these deliberation councils would come up with a plan of action.

The second element of the intervention is to create a centralized budget that can be allocated to different public entities so that they have the resources to provide the requisite public good. This may be money for infrastructure, for improved phytosanitary services, or for a new regulation. The centralized budget enables the entity dealing with the private sector to buy the necessary services from the many, disparate executing public entities that provide them.

This helps reduce the incentive problem mentioned above. To see why, consider the parallel with private markets. In markets the prospect of profits provides the incentive for action. In our case, the profit motive is substituted by whatever incentivizes the ministry to be responsive to the private group. A centralized budget fulfills this function by inducing competition for resources among different government entities, thereby approximating a "market" for responsiveness. Entities can increase their resources above allocated amounts by "bidding" on centrally funded projects and in the process committing themselves to reach well-defined goals. We say such bidding approximates a market because in many cases government departments or agencies will have, by law, exclusive jurisdiction for the writing of rules or the provision of services in a given domain. In such cases the accountability mechanism of contracting with and monitoring by the central fund, rather than market competition among providers, ensures heightened responsiveness. The fact that central funds can only be transferred to other public entities, and that these entities may contract with private service providers when internal capacities are insufficient means that in principle these funds are only for public inputs, not outright transfers, and also that they can motivate the government to undertake tasks beyond its current reach.

Notice that the central fund aims to achieve, gradually and in the long run, the same alignment of government action to actual need that zero-based budgeting and related instruments have tried, in vain, to effect all at once. As actors learn to meet the fund's eligibility criteria, and competition for its resources increases, we expect bidders - coalitions of firms and the government entities with which they are cooperating - to increase the attractiveness of their proposals by increasing their commitments to co-invest: that is, offering the central fund the opportunity to "buy" more and more reform in their part without a corresponding increase in its expenditures. Change at the innovative margins of government would thus incrementally entail change at its entrenched and unresponsive infra-marginal core-change that, experience shows, can not be produced by even the most emphatic command to reassess the utility of all existing programs.

The third element of the intervention is to create a method of monitoring that allows the system to generalize its successes but also to detect and learn from its mistakes. We said earlier that we see industrial policy as a set of collaborative policies and procedures for detecting and responding to distortions in the economy. In a volatile world these policies will themselves be flawed, in ways that change with circumstances. 
To continuously adapt and improve them, we need a routine that not only identifies systemic flaws in current decision making, but also helps to diagnose their cause, and highlight exceptional cases where some decision makers found a way around the problem.

Drawing on innovations in public and private governance that aim precisely to improve institutional response to shifting, high-dimensional problems like those posed for industrial policy, we therefore propose an annual diagnostic or "quality" review of one key project of each deliberation council. The review teams would consist of two or three members with an appropriate mixture of expertise: a manager from a leading multinational in the relevant lines of business, an official from a widely admired development agency in another developing country, and the leader of a highly successful deliberation forum in another sector. In a two day site visit, the team would review the documentation of the project and discuss its status with the stakeholders, including not just the relevant firms and service providers, but also actors in a position to judge the performance of both - for instance, selected customers and suppliers to the firms and participants in training and capacity-building programs. This review is disentrenching: it aims to uncover and eliminate routines and habits that obstruct the search for effective solutions. The focus would be on three questions: Did the deliberation council initially include all those with the relevant capacities and interests, and if not, was its membership modified so that it did? Did the discussion of possible projects canvas plausible alternatives, and was the final choice well motivated? Has the project met its milestones, and if not, is there a clear understanding of why and a corresponding adjustment of the project's goals and timetable? The findings for each project would be reviewed for error with the principal decision makers in the deliberation forums. Then all the findings would be discussed in a joint meeting of review teams to identify systematic flaws in decision-making as well as generalizable solutions to recurrent problems. The upshot would be modifications in the guidelines for organizing and conducting deliberation forums: an improvement in the framework of decision-making and a clarification of its possibilities. Problems specific to particular projects would prompt corresponding action plans, and subsequent reviews would see to what effect these plans had been put into effect or corrected. We imagine a similar process for the diagnostic review of project selection and monitoring by the central fund and for the key institutions of industrial policy in the large, to be discussed below.

Finally, this process has to be further disciplined and directed by some set of operational rules. The plans of action that the deliberation councils generate will entail actions by different ministries and public entities. For incentive reasons, we would in general discourage transfers to the private sector. Direct subsidies may be justified in some cases, but they would create incentives that would detract attention from the identification of the requisite public goods. We would consider providing some support in order to solve the free-rider problem, but that would impose a co-financing requirement so that proposals for transfers would need to pass some willingness-to-pay test. The actions taken would be public knowledge and would go through some mechanism in order to guarantee that they solve problems for as wide a potential set of 
activities as possible. This implies that we want to maximize spillovers from problem identification.

The list of operational criteria could be made more precise. Many of these are listed and discussed in Rodrik (2004) and Hausmann and Rodrik (2006). Here is a short list of principles:

a) Keep the dialogue structure open; let the private sector self-organize.

b) Impose transparency principles in order to limit rent-seeking and increase legitimacy vis-à-vis the rest of society.

c) Prioritize public inputs: this justifies why the government needs to get involved. There may be a case for fostering private-private cooperation, but the case for public involvement is weaker. Benchmarking clubs and trade associations seem to form without much coaxing.

d) Interventions are to be chosen so as to increase productivity, not in order to compensate sectors for their low productivity or to prop up at risk communities by subsidizing local economic activity in the guise of industrial policy. Other programs can of course legitimately serve that purpose.

e) Establish clear criteria for success for interventions ex-ante, so that nonperformance is diagnosed earlier and can be corrected.

f) Sunset clause: Money from the centralized budget may be temporary in nature, as when it is dedicated to develop a new law or regulation or an infrastructure project. Money for longer term interventions such as labor training would be supported for a while, but then would have to be incorporated to the budgets of those institutions.

g) Streamline decision-making and execution: develop a mid-level horizontal mechanism for the allocation of the central budget to flow to the executing agencies without having to go through the Cabinet or Economic Cluster meetings. Bilateral agreements between executing agencies and the DTI (or any other ministry with a central budget) would create a system of green, yellow and red lights. Things would go up the level of seniority depending on the color of the light.

h) Accountability: The quality service review will do part of the work here, but far from all. Financial controls will need to be in place. There will have to be clear guidelines for deciding when to let losers go, and those guidelines will have to be refined by the same means as other administrative instruments.

i) Universalize: Build a formal process whereby an initiative may be re-designed or expanded in order to benefit more activities. Again the quality review will 
be part, but only part of the answer. Regular horizontal exchanges among deliberation forums and vertical exchanges between the central fund and the forums about what is working and what is not should be established - and the effectiveness of those exchanges should be diagnostically reviewed, perhaps biennially.

\section{Industrial policy "in the large": strategic bets}

Institutional arrangements such as those described above may be good for enhancing production possibilities around existing capabilities, but they will not produce the leaps that are often required to sustain economic growth - from coffee to garments, from garments to electronics, or from electronics to biotechnology.

A major difference here is the degree to which intentionality is required. Industrial policy in the small largely entails the improved provision of public inputs. It neither supposes nor produces anything resembling a master plan. The hope is that, as the provision improves, more productivity and quality improvements will result, and more jumps to nearby "trees" in the forest of productive activity will take place. What guides the process are actors' complaints and the attractiveness of the solutions they identify (call this the policy of the cogently squeaky wheel). The government is not expected (and would not be able) to predict what these are. By contrast, industrial policy in the large implies thinking of an industry or an activity (for instance, an entrepot of certain kind) one would want to see develop, and then backing up all its public input needs plus some subsidies to get the private juices going. This requires more centralization and more prioritization: which customized sector programs we design, how we assure coordination between the different complementary public inputs, who is in charge of guaranteeing the coordination, and so on. It calls, therefore, for a second set of institutions that can range much wider in its exploration along the frontiers of the production space than can deliberation councils, and which are thus able to stimulate capacity-building "jumps."

What might such institutions look like? One possible model is that of a venture fund: an institution that is continuously scouting for opportunities, which has the technical capacity to evaluate projects and their proponents as well as the financial resources to get business plans off the ground; can recognize the new venture's mistakes as they occur; can orchestrate their correction or, failing that, pull the plug; and is guided by the bottom-line concern to generate profitable companies that the private sector will want to take over. In these ways venture funds resemble the private-sector venture capitalists on which they are modeled. However, there are important differences. The venture capitalists in a developed economy are typically many, and they compete for the best of the many deals presented to them. In developing countries the public venture fund is likely to be a de facto monopolist, and to have to generate ideas for strategic projects rather than choose among them. More precisely, the venture fund has to oscillate between organizing coalitions to support its projects, or championing and developing the 
projects through loose and often fragile coalitions of innovators. Since choices are in neither case disciplined by competition with other similar institutions, it is not surprising that in the few developing countries that have public venture funds, the guiding motives were often more political than economic. Electronics and autos in Malaysia provide two illustrations, one successful, the other less so. Chile is one of the rare exceptions, where Fundación Chile has operated much like a public venture fund. It is said that five of the most successful projects undertaken by Fundación Chile, salmon being the best known, have paid for all the rest.

In some countries the requisite capabilities for developing a public venture fund are often lodged in development banks. Development banks, such as those in Brazil, Turkey, and South Africa, have technical expertise, close knowledge of the real sector, financial resources, and some degree of autonomy from the daily pull-and-push of politics - all of which make them suitable for the execution of the venture fund role. Development banks have been typically seen as sources of long-term finance and have been used for various social and commercial goals. We can rethink them as instruments of strategic bets in the sense used here - as sources of ideas about high return activities and about the obstacles that need to be addressed to increase the chances of success of projects that attempt to realize those ideas. This is particularly useful for strategic projects where the relevant actors will not come knocking at your door.

For example, if the government thinks that medical drugs are a sector it may want to see develop, the development bank will look for projects in this area. It would evaluate options, marshalling evidence that allow it to evaluate the feasibility of the idea from competing but mutually informative perspectives. In the process of doing this it would contact and assess potential partner. Here the venture fund is on a tightrope - if it is too easily swayed by those it consults, it can be captured by them; if it abuses its dominant position and takes their ideas without affording them fair terms for participating in an eventual project, it can isolate itself from and antagonize indispensable supporters. Again, regular diagnostic review of project development may help in making sure that the balance is right. As projects crystallize, the development bank, as champion of an industry in the making, would undertake the broadest feasible search to identify missing or deficient public inputs and lobby the government for requisite changes.

The public venture fund needs to base its decisions on clear benchmarks/criteria for success and failure. Industrial policies are necessarily experimental, and strategic leaps of the type envisaged here are the most experimental of them all. In Korea, Taiwan, Chile, and a few other countries, successes have more than paid for the mistakes. Without clear ideas of what constitutes success and observable criteria for monitoring it, failures are easily entrenched. In the tradable sector an indispensable performance metric is productivity - both its rate of increase and its absolute level. Increases in employment or output unaccompanied by improvements in productivity are almost surely unsustainable. While productivity is notoriously difficult to measure in general, virtually every domain in the tradable sector now establishes, and frequently updates benchmarks regarded as serviceable proxies. Firms that do not measure their progress by these international benchmarks are unlikely to keep up with those that do. So the venture fund 
can reasonably expect the projects it supports to benchmark themselves in the relevant ways, and then draw on these and other routine comparisons (of export levels, for example), as well as project audits by business and technical consultants to judge the progress of its undertakings.

Many promoted activities will necessarily fail. But this is as it should be. The absence of failure is a sure sign that the government's industrial policies were too timid. The ultimate test of whether industrial policy is working is not whether a government can reliably pick winners (no government reliably can) but whether a government is able to let losers go. The objective should be not to minimize the risk of mistakes, but rather to minimize the costs of the mistakes that inevitably occur on the way to success.

\section{An application to South Africa}

We said above that the acid test for an industrial policy framework is whether there exist institutions that engage policy officials in an ongoing conversation with the private sector; whether the government has the capacity to respond selectively, but also quickly and using a variety of policies, to the economic opportunities that these conversations are helping identify; and finally whether there are monitoring and evaluation procedures to ensure the policy process is self-correcting.

South Africa has at present a plethora of instruments and agencies involved in formulating and implementing industrial policies. The Department of Trade and Industry (DTI) is in charge of developing customized sector programs (CSPs), administers the Motor Industry Development Program (MIDP), and provides a wide range of cash and other incentives. The Department of Public Enterprises has a large capital expenditure program that aims to develop local supplier capacity through its Supplier Development Program. The Department of Minerals and Energy is in the midst of formulating a program to encourage beneficiation (downstream processing) of minerals such as diamonds and titanium. The Industrial Development Corporation (IDC) is engaged in financing SMEs and BEE equity deals and invests in some self-discovery activities. In addition, provincial governments have their own investment promotion agencies (such as Wesgro in the Western Cape) to facilitate investment in their regions.

Despite this range of activities, we do not believe that current policies pass the acid test above. There is too much disconnect between the private sector and the government, information does not flow adequately, needs are not well identified, policy instruments are not appropriately targeted, and self-correction mechanisms are not in place. The good news, however, is that many elements of a better policy apparatus are already in place. In some important cases we think it is possible to build on existing institutions, expanding some of their activities while substantially reducing others - in other words, rebalancing their portfolios. At the opposite extreme are programs that have outlived their usefulness and have to be re-founded to serve the purposes for which they were originally conceived. In between, as it were, are cases where current arrangements are so disorganized that we think it advisable to create institutions with overlapping 
responsibilities and let competition between old and new bring out the best in both. Finally there are initiatives needed to improve the background or framework conditions within which industrial policy takes place, and it is with the most important of these that we begin.

1. A new budgetary procedure to elicit information on missing public inputs and pay for them.

We propose that every year a certain share (4\%) of economic cluster department budgets be allocated to a central fund the main purpose of which is to finance specific public inputs. Allocation of funds would be made on the basis of proposals coming directly from the private sector. As indicated above we interpret "public input" broadly: A public input may consist of infrastructure (road improvement), training (artisanal skills for a specific industry), fast-track bureaucratic procedures (work visas for skilled immigrants), research and development activities, or a piece of legislation (regulatory framework for biofuels). The chief criterion would be that the input enhances productivity (and not just profitability). Preference would be given to projects that enhance productivity in the tradables sectors. The fund would solicit proposals from firms or groups of firms, which would then be vetted by a technical secretariat. An interdepartmental committee would make the final decisions. In exceptional cases, when the goal of projects is to establish long-lived training or research organizations, public taxing authority may be delegated to public-private bodies, contingent on continuing demonstration that they are meeting agreed objectives and that the tax is levied only on its members. The rules determining the boundaries of membership in an economic grouping to which taxing authority is to be delegated are established in consultation with the potential members of the group. The group can cease to exercise the delegated power to tax itself upon the vote of a supermajority determined when the group is formed. Whether or not taxing authority is delegated, the rules governing the formation of project groups should make them easily contestable by dissident members or by new groups with similar or even identical goals.

This proposal thus does double duty. On the one hand it increases the responsiveness of government as a whole to the needs of industrial policy and its legitimate beneficiaries, as discussed above. On the other hand it creates a de facto competitor to the Customized Sector Programs as a sponsor for the whole range of projects associated with industrial policy in the small. We give reasons for proposing this competitive overlap of responsibilities below.

Notice that this proposal is not unprecedented in South Africa. In many ways it is similar to the Critical Infrastructure Fund (CIF) that the government has already put into operation. But our proposal differs in three key respects. First, there would be no restrictions on who can apply for the funds, subject to the preference for firms that are directly or indirectly involved in the production of tradables, as we noted above. Second, "infrastructure" would be interpreted broadly to include any public input that enhances private-sector productivity. Third, we have in mind a much larger fund, one that can have a real impact on the investment and capacity decisions of private firms. 


\section{Reorienting the IDC towards self-discovery activities}

The IDC is ideally positioned to undertake self-discovery activities: scanning the economy for investment opportunities in new industries, lending or taking an investment position in the early stages of the development of the industry, and communicating information about obstacles and constraints identified during the process to the relevant agencies of the government. There are exceptional instances in which IDC has acted in precisely this way. The role that institution has played in the development of the berry sector and in cashews provides examples of the kind of activity we have in mind. We would like to see this becoming the core of IDC's portfolio, not a peripheral activity. What makes the IDC all the more relevant in this context is that it sits on a large asset base with very low leverage and turnover ratios. The institution has plenty of room to expand and to engage in the strategic bets that we discussed above.

The problem is that IDC engages in self-discovery activities all too rarely. The bulk of its resources go to either conventional projects or to SMEs and BEE financing. Essentially, we would like to see IDC act much more like a venture fund and much less like a commercial bank. This entails becoming much more pro-active in scanning for investment opportunities in new economic activities (which the IDC is well positioned for, given its staff), more willing to get involved in the very early stages of an industry's development and in greenfield investments, and having a greater appetite for project risk. Trying to ensure that none of its investments fail makes no sense in a self-discovery context. The institution should instead strengthen its monitoring activities to ensure that it has the capacity to recognize and get out of failures.

\section{A revamped MIDP focused on strengthening the supplier base}

The existing MIDP program has fulfilled its goal of retaining and growing an auto industry that has the potential of becoming competitive in the global industry without government support - but the industry is not there yet. We provide an evaluation of the MIDP in the appendix to this paper. Going forward, the central issue faced by the sector is one of large-scale coordination. Many (but not necessarily all) of the OEMs can see a path of scaling up to a level at which they can be competitive, but they are in need of a well-developed domestic supplier base for this to become a reality (in view of the logistics cost of importing components from great distances). Potential first-tier suppliers themselves, on the other hand, have to operate at large scale to meet the needs of the OEMs, but they are hesitant to make the investment in South Africa if that means that they will be tied to a single OEM and therefore left hostage.

The solution is to focus the incentives away from exports and towards incentivizing capacity expansion and generation in supplier industries directly. We would recommend a gradual phasing out of the IRCC scheme, and its replacement by a supplier-base promotion scheme that consists of two "windows:" 
a) A standard incentive that takes the form of a subsidy on the wage bill or the capital cost for new capacity by first-tier suppliers to OEMs.

b) An 'open window' where the support depends on specific needs of the firms in question. Such needs might, for example, include accelerated depreciation of investments in new capital goods, the formation of research consortia (to develop next generation technologies and so reduce the current burden of licensing fees), or supplier qualification institutes that would pool the expertise of the most capable customers and public entities in the industry while allowing suppliers to reveal and address weaknesses without jeopardizing possible business relations.

Qualifying firms would be asked to choose between the two windows. The idea is to give firms the option of making specific demands that fit their own requirements best. The scheme has the added advantage that it would allow the government to learn about the obstacles faced by investors in the industry.

Under our proposed scheme, not all OEMs will necessarily find it profitable to remain in South Africa or to ramp up their operations. Our sense is that some of the OEMs are hooked on the rents generated by the IRCCs, and any phasing out of these, as we are recommending, will be met by stiff resistance and threats of closure and exit. At the same time, the long-term health and sustainability of the industry depend on screening out and separating those firms that are interested in producing in South Africa purely because of subsidies from those that can see a path to unassisted competitiveness. Our proposal is aimed, among other objectives, at achieving this screening. It would be important in this context for the government to communicate its new objectives and policies to the industry quite clearly and in no uncertain terms. Firms that are unable or unwilling to make a commitment to creating a supplier base, even with the incentives provided towards that end, are probably not worth keeping.

\section{Improving the CSP processes}

Ideally, the kind of policy that we have advocated for the auto industry would have come out of the CSP process for the sector in the DTI. In principle, the CSP consist of a deliberation forum at the industry level and would function along the lines that we sketched in the earlier discussion of industrial policy in the small. Elements of such a deliberation forum have indeed been sponsored under the umbrella of the MIDP, most notably the benchmarking club of assemblers. Though neither this club, nor any other forum or oversight body created in connection with what is, after all, South Africa's single most significant and conspicuous industrial policy program managed to articulate a reorientation plan that most key actors would regard as reasonable - and this occurred despite the obvious need to issue new regulations because of the MIDP's inconsistency with WTO rules and the expiration of the present scheme. The inability to effectively engage key suppliers in a discussion that explicitly, and ever more urgently, 
acknowledges their centrality seems especially troubling and revealing. All this points to a failure of execution and monitoring in the government's efforts to organize policy collaboration with industry. We found related disjunctions between dialogue and policy in the CSP for the BPO and capital equipment sectors, although we were unable to diagnose their systemic cause. More precisely, we concluded the CSP is not a systematic program with characteristic advantages and disadvantages at all, but rather it is a collection of very disparate industrial policy initiatives grouped under a common rubric. In the capital equipment industry, the "process" resulted in a rich dialogue between the DTI and the sector, but the broader policy system appears to have failed to respond to this discussion appropriately and with requisite speed. In the BPO sector, the "process" produced a useful market analysis, which led to a strategic bet on the industry and temporary wage bill subsidies to encourage new investments - but (so far as we can see) with no specification of criteria for success, no monitoring of progress, and no continuing discussion with the emergent industry about possible next steps.

Given these difficulties we think it advisable to supplement the CSP with the project selection and monitoring mechanisms established in connection with the central fund.

\section{Avoiding forced beneficiation}

There has been much talk in South Africa about the need to increase beneficiation of domestic mining resources. We think that beneficiation, in the sense of incentivizing the domestic processing of natural resources, is not a sensible policy. The capabilities developed through mining can be exploited in a number of different ways, but these potential developments are only accidentally connected to the further processing of ores and minerals. For example, the skills involved in cutting and polishing diamonds and in the jewelry industry are quite different from those involved in mining diamond ore. Meanwhile, the needs of mining generate a host of skills and capabilities in the design and production of high performance pumps and valves and other capital equipment for the mining industry. These capacities can be further applied and developed not only in mining but in many other industries worldwide. A policy focused on beneficiation has such a narrow focus that it tends to encourage the wrong activities and generates inefficiency.

The beneficiation policy of the Department of Minerals and Energy is still under consideration, but what we have heard suggests that the current policy is not very aggressive. In diamonds, there is a 5\% export levy, which is low and not a great source of concern. Mining firms are given the option of offsetting their BEE obligations by investing in downstream processing. This is not too problematic although it is not optimal. To the extent that it enlarges the menu of options available to mining firms for discharging their developmental "duties," it is an improvement over current practice. A superior approach would be to extend this offset option to domestic investments in tradables that do not lie downstream (and hence do not take the form of beneficiation proper). As a practical matter, the costs of beneficiation are likely to be measured less in 
the poor investments it compels than in the opportunities it obscures. The conviction that the capabilities of mining firms are best deployed downstream of their activities and the closely related (though usually unspoken) presumption that value created in mineral processing has greater economic and social impact on the economy than value added in other tradable activities are legacies of the older view of industrial policy and its core presumption that the path of development is determined by the nature of things. That legacy frustrates the open-ended search for possibilities that the industrial policy proposed here is designed to encourage.

\section{Concluding remarks}

Industrial policy assists firms in their search and discovery processes for new lines of comparative advantage. As we have tried to make clear, the implementation of industrial policy itself is a process of discovery about the appropriate institutional practices that will bring the desired results about. That is why benchmarking, monitoring, and experimentation are so important. Internalizing what industrial policy is about - and continuously striving to bring practice in line with its objectives - is ultimately perhaps more important than making sure one starts with the "right" set of policies.

The most important lesson from East Asia is that industrial policy is a mindsetone that rejects big-bang, all-at-once reforms in favor of experimentation, gradual, but cumulatively transformative change through identification of bottlenecks and selfcorrection: small investments at the outset of projects (even when they involve strategic bets) but continuous, well organized attention to making them work. 
Appendix: A note on the economics of the MIDP and IRCCs

There is considerable debate among analysts in South Africa about the extent to which the MIDP has been successful. Some of the indicators clearly point to industrial policy having been effective in this sector: the MIDP has kept major OEMs invested in the South African economy, production has been rationalized, productivity is high (for OEMs and first-tier suppliers), and exports have increased substantially. Positive assessments of MIDP, such as that of Barnes, Kaplinsky and Morris (2003), point to these favorable developments. On the other hand, import tariffs on finished vehicles still remain high (at 30\%), suggesting considerable consumer costs, and the fiscal cost of the duty rebates granted through the IRCC scheme is also quite significant. Critics such as Flatters (2005) point to those costs in arguing for the scrapping of MIDP.

As we have argued in the body of this paper, MIDP needs to be reoriented from a scheme that subsidizes exports through import duty rebates to one that encourages upstream and supplier linkages directly. Whatever costs MIDP may have generated, it has created the foundations of a sustainable motor vehicle industry which our visits have confirmed can become globally competitive (without protection or export subsidies) if the domestic supplier base is broadened and deepened. That in turn requires a new set of policies geared towards enhancing coordination between OEMs and suppliers, as outlined in the main body of the paper.

Hence we favor the phasing out of MIDP incentives in their current form, primarily because these no longer target the main binding constraints the auto industry faces. A detailed accounting of the economic benefits and costs of MIDP is therefore not necessary. However, a simple framework for thinking through the effects of the IRCCs can still be helpful, as it may help sort out conflicting claims in the literature. While the MIDP has many elements, we focus here on the IRCCs in particular.

What is the counterfactual?

In order to evaluate the IRCC scheme, we need to be clear about the relevant counterfactual. In the absence of the IRCCs, import tariffs on cars would most likely have been lower, although probably still non-zero. It seems reasonable to suppose that the relevant counterfactual is one where there are no IRCCs and trade liberalization in the auto industry matches the average for the rest of manufacturing industry. With this assumption, we can treat trade, output, and employment indicators for non-auto manufactures as the counterfactual baseline for motor vehicles. So if we run a panel regression across three-digit manufacturing industries, a post-1995 (MIDP) dummy for the auto industry would pick up the effect of MIDP on sectoral outcomes due to MIDP.

The results of such an exercise reveal that the MIDP has had a large impact on exports and virtually no impact on import penetration (relative to the counterfactual just discussed). It also has had an employment boosting impact in the auto industry of around 15 percent. These results seem sensible, although the negligible impact on imports is interesting and needs further comment. Why is it that imports seem unaffected despite 
the higher tariffs? This may seem puzzling at first sight, but it is actually in line with the logic of the MIDP. By rebating import tariffs, the IRCC scheme encourages OEMs to import vehicles. The import-repressing effect of the higher tariff is offset by the importboosting effect of the duty rebate. The numbers indicate that these two countervailing effects on import volumes have roughly canceled each other out.

\section{$\underline{\text { The welfare-analytic framework }}$}

Essentially the IRCC scheme is an export subsidy, whose value to the producers depends on the import tariffs levied on vehicles and parts. To account for the conventional economic distortions created by such a policy, it helps to start from the simplest textbook model and append the relevant South African detail in the second step. So suppose to begin with that there are no other economic distortions and that the auto industry is fully domestically owned. The IRCC scheme then creates the following two distortions:

a) an import-repressing effect because of higher tariffs (the first-order cost of which is $t \Delta m)$.

b) an inefficient-exports effect due to the export subsidy (the first-order cost of which is $s \Delta x)$.

However, as we have just pointed out, the export subsidy has also served to boost imports in second-best fashion, so in fact effect (1) is largely inoperative. Effect (2) also needs careful interpretation, for two reasons. First, OEMs are foreign-owned, which means that we need not track the part of the inefficiency that is paid for by these foreign companies. Second, in light of high unemployment, a net expansion of employment in the industry has to be counted as a plus for the economy - not as a minus. Assuming for simplicity (and not too unrealistically) that all profits go to foreign-owned companies, term (2) vanishes as well, to be replaced by a new term that tracks the employment surplus.

So we now adjust our accounting for these two factors. On the employment front, if the social opportunity cost of labor is $w^{*}$, the industry's expansion (through exports and domestic sales) generates a net employment surplus equaling $\left(w-w^{*}\right) \Delta l$, where $w$ is the average wage in the industry and $\Delta l$ is the net employment creation due to MIDP. To some extent, this also incorporates any productivity gains the industry has experienced due to MIDP, as the only nationally relevant part of that gain is the component that is reflected in industry wages.

There are two additional wrinkles created by foreign ownership. One is that the IRCC rebates accrue to foreign companies: they are a transfer from domestic consumers (who pay higher import prices) to the foreign OEMs, through the fisc. Let's denote the value of IRC certificates by $C$, the average export-import conversion factor by $k$, and the average level of import duty foregone by $t$. Then the loss to national income equals on this account equals $t k C$. Secondly, foreign OEMs also make higher profits (at the expense of domestic consumers again) on units they sell domestically, due to higher 
tariffs. Letting the counterfactual tariff be $t^{\prime}$ and domestic sales of autos be $Q$, this loss is equal to $\left(t-t^{\prime}\right) Q$. Previously, when we assumed domestic ownership, we did not need to track either of these redistributions separately, as they entailed a transfer from one domestic group to another.

Hence the three effects that determine the net (static) costs or benefits of the program can be written as follows:

a) a net employment surplus, equal to $\left(\mathrm{w}-\mathrm{w}^{*}\right) \Delta \mathrm{l}$

b) a transfer to foreign companies (loss), equal to tkC

c) a transfer to foreign companies (loss) equal to ( $\left.t-t^{\prime}\right) \mathrm{Q}$.

These ultimate effects look very different from those in the textbook model, due to the special wrinkles we have discussed.

$\underline{\text { Some calculations }}$

With this framework in place, we can play with some numbers to arrive at rough orders of magnitude. We present some illustrative calculations for 2005.

Note that the maximal gain on account of (1) comes if we assume that all the additional jobs generated by MIDP were filled by workers who would have been unemployed otherwise (in effect setting $w^{*}=0$ ). Even with this assumption, it is hard to make the numbers look good for the MIDP. Given our estimate that MIDP increased auto sector employment by around $15 \%$ and a 2005 total employment of 108,000, the net employment creation that is due to MIDP is around 14,000 jobs. Since average labor remuneration in the sector is R144,000 per annum, the (maximal) net employment surplus stands around R2 bn.

Compare this figure to the loss on account of IRCC transfers to foreign OEMs (effect 2). In 2005, the total value of IRCCs issued was around $\$ 17 \mathrm{bn}$. Assuming a conservative export-import conversion rate $(k)$ of 0.65 , and using the actual tariff on vehicles $(t)$ of 0.34 , the loss on account of channel (2) alone stood at R3.8 bn. This is substantially larger than any net gain on the employment front.

These calculations make clear why MIDP needs significant reform and why the existing incentive structure is no longer adequate. It is not targeted on the binding constraint, and it is a net drain on the national economy even under the most favorable assumptions.

\section{Overlooked benefits?}

Does this analysis leave out any potential benefits of MIDP for which we have not accounted? One possibility is that the program has induced OEMs to reduce the domestic 
prices of their vehicles. The analysis above assumed that domestic car prices equal landed world prices plus the tariff on imported vehicles. It is possible, if not entirely likely that, the OEMs pass on some of their tariff savings through the IRCCs to the South African consumers. In that case, the increase in domestic prices (relative to the counterfactual) would be less than $t-t^{\prime}$, and the costs highlighted in effect (3) above would be lower. It is highly unlikely that this would change the relevant magnitudes much.

A second issue is that we have not accounted for the induced employment effects of MIDP outside of the auto industry. The employment benefits could be larger is these linkages create additional net employment elsewhere in the economy. In principle, it may be possible to derive an outer bound on this by using input-output tables. Though once again, this is unlikely to change the conclusion much once we make the realistic assumption that not every job created by MIDP (directly or indirectly) is a pure addition to total employment. The transfers being made to foreign OEMs under the IRCC scheme (effect (2)) are too large for the rest of the numbers to make much of a difference to the bottom line. 


\section{REFERENCES}

Barnes, Justin, Raphael Kaplisky and Mike Morris. "Industrial Policy in Developing Economies: Developing Comparative Advantage in the South African Automobile

Sector." Available at http://www.ids.ac.uk/ids/global/pdfs/RJ\&JB03.pdf. May 2003.

Flatters, Frank. "The Economics of MIDP and the South African Motor Industry. Available at http://qed.econ.queensu.ca/faculty/flatters/writings/ff_economics_of_midp.pdf. November 2005.

Hausmann, Ricardo, and Dani Rodrik, Doomed to Choose: Industrial Policy as Predicament, Harvard University, September 2006.

Rodrik, Dani, Industrial Policy for the Twenty-First Century, Harvard University, September 2004 